\title{
Validity of echocardiographic estimates of left ventricular size and performance in infants and children
}

\author{
H. H. Kaye, Michael Tynan, and Stewart Hunter \\ From the Department of Cardiology, Newcastle General Hospital, Newcastle upon Tyne
}

Echocardiography has been shown to be a reliable method for estimating left ventricular size and function in adults, but little attention has been paid to its application to infants and children. This paper describes a validatory study in 40 children aged between 4 days and 16 years. There was a significant correlation between angiocardiographic and echocardiographic estimates of left ventricular end-diastolic volume $(r=0.76)$, left ventricular end-systolic volume $(r=0.68)$, and ejection fraction $(r=0.73)$. Left ventricular mean circumferential shortening rate (mean $V c f)$, however, gave the most significant correlation $(r=0.9 I)$.

These findings indicate that while care must be exercised in interpreting indices of left ventricular size and performance derived from echocardiography, these measurements, and in particular mean Vcf, do offer a useful and reliable means of assessing left ventricular function in infants and children.

Single probe echocardiography has been proposed as a reliable non-injurious method of estimating left ventricular (LV) size and function (Feigenbaum et al., 1969; Gibson, 1973; Pombo, Troy, and Russell, 1971; Popp et al., 1969). The technique is particularly appropriate for infants and children since it causes no discomfort and can be carried out in the presence of the parents, thus minimizing anxiety. Most validatory studies have been performed on adult patients and little work has been done to confirm the validity of the measurements in children (Sahn et al., 1974). In this paper we present such a study with data obtained from angiocardiography and echocardiography in a group of infants and children, including patients with a wide variety of congenital heart defects.

\section{Patients and methods}

Forty patients aged 4 days to 16 years (mean age, 4 years 5 months) were studied. All patients underwent clinically indicated cardiac catheterization and angiocardiography. During the course of this investigation left ventricular size and function were assessed by quantitative single plane cine ventriculography. Volumes were calculated using the area length method with appropriate correction for magnification and distortion

Received 17 September 1974.
(Dodge, 197I) and corrected according to the formula derived from our validatory study:

True volume $=0.59$ (calculated volume) ${ }^{1.09}$.

These methods are described in detail elsewhere (Tynan et al., 1975). Mean rate of circumferential shortening (mean Vcf) was calculated according to Karliner et al. (197I).

The echocardiographic study was performed in the cardiac catheterization laboratory, with the patient sedated, immediately before the start of the cardiac catheterization. The echocardiographic examination was performed using an Ekoline 20 Ultrasonoscope with a 2.25 MHz focused transducer. Echocardiograms were recorded on polaroid photographs from the face of a storage oscilloscope. Left ventricular dimensions were measured where the interventricular septum and posterior ventricular wall were visualized simultaneously with the anterior and posterior mitral valve cusps. Patients with paradoxical septal movement were not included in the study. The end-diastolic dimension was measured at the peak of the $R$ wave of the simultaneously recorded electrocardiogram and the end-systolic dimension at the point of closest approximation of the posterior left ventricular wall and the interventricular septum. Echocardiographic estimates of left ventricular enddiastolic volume and end-systolic volume were obtained by cubing the end-diastolic dimension and the endsystolic dimension respectively (Feigenbaum et al., 1969; Popp et al., 1969). Ejection fraction was calculated in the usual way. Absolute values of end-diastolic volume and end-systolic volume were corrected for body surface area. Mean velocity of circumferential 
TABLE I Ages, diagnoses, and angiocardiographic and echocardiographic estimates of $L V$ size and performance

\begin{tabular}{|c|c|c|c|c|c|c|}
\hline \multirow{2}{*}{ No. } & \multirow[b]{2}{*}{ Age } & \multirow[b]{2}{*}{ Diagnosis } & \multicolumn{2}{|c|}{ Angiocardiographic values } & \multirow[b]{2}{*}{$E F$} & \multirow[b]{2}{*}{$\begin{array}{l}\text { Mean } \\
\operatorname{Vcf}(\operatorname{circ} / s)\end{array}$} \\
\hline & & & $E D V\left(m l / m^{2}\right)$ & $E S V\left(m l / m^{2}\right)$ & & \\
\hline I & $4 d y$ & PAT & 63.3 & 21.2 & 0.66 & 0.92 \\
\hline 2 & $2 \mathrm{wk}$ & Coarct and VSD & 26.5 & 7.5 & 0.71 & 2.00 \\
\hline 3 & 2 wk & Coarct & 47.6 & 9.5 & 0.80 & I.2I \\
\hline 4 & 4 wk & PDA & 47.0 & 6.0 & 0.87 & 2.76 \\
\hline 5 & 7 wk & PHMD & 154.0 & 99.0 & 0.36 & 0.14 \\
\hline 6 & 8 wk & PDA & 93.8 & 24.8 & 0.74 & 1.30 \\
\hline 7 & 8 wk & VSD & 46.5 & 3.5 & 0.92 & 3.25 \\
\hline 8 & 3 mth & PHMD & 227.0 & 213.0 & 0.06 & 0.07 \\
\hline 9 & $4 \mathrm{mth}$ & TGA & 65.0 & 19.4 & 0.70 & 1.45 \\
\hline 10 & $4 \mathrm{mth}$ & PDA & 107.0 & 31.7 & 0.70 & 1.71 \\
\hline II & $6 \mathrm{mth}$ & Coarct and MR & 43.5 & 13.5 & 0.69 & r.59 \\
\hline 12 & $6 \mathrm{mth}$ & TGA & 131.0 & 55.0 & 0.58 & 1.25 \\
\hline 13 & $9 \mathrm{mth}$ & PDA and VSD & 94.0 & 37.0 & $0.6 \mathrm{I}$ & 1.15 \\
\hline 14 & $13 \mathrm{mth}$ & PDA & 159.0 & 37.0 & 0.77 & 1.31 \\
\hline 15 & $2 \mathrm{yr}$ & PS & 73.0 & 14.0 & $0.8 \mathrm{I}$ & 1.72 \\
\hline 16 & $3 \mathrm{yr}$ & PDA and CHB & 234.0 & 60.7 & 0.74 & 0.70 \\
\hline I7 & $3 \mathrm{yr}$ & TGA and VSD & 38.0 & 12.0 & 0.67 & 1.33 \\
\hline 18 & $3 \mathrm{yr}$ & PDA & I19.0 & 37.0 & 0.69 & I.17 \\
\hline 19 & $4 \mathrm{yr}$ & PS & 60.0 & 21.0 & 0.65 & 0.91 \\
\hline 20 & $5 \mathrm{yr}$ & PS & 73.4 & 12.6 & 0.83 & 1.39 \\
\hline 21 & $5 \mathrm{yr}$ & PHMD & 131.5 & II8.5 & 0.10 & 0.10 \\
\hline 22 & $5 \mathrm{yr}$ & PDA & 98.8 & 32.5 & 0.65 & 1.08 \\
\hline 23 & $6 \mathrm{yr}$ & TGA and BT & 109.5 & 27.8 & 0.75 & 1.96 \\
\hline 24 & $6 \mathrm{yr}$ & VSD & 147.7 & 46.4 & 0.67 & 2.08 \\
\hline 25 & $6 \mathrm{yr}$ & PVT & 91.0 & 35.0 & 0.62 & 1.17 \\
\hline 26 & $6 \mathrm{yr}$ & VSD & I52.0 & 29.0 & $0.8 \mathrm{I}$ & 1.76 \\
\hline 27 & $6 \mathrm{yr}$ & PS & 139.0 & 37.0 & 0.73 & 0.89 \\
\hline 28 & $6 \mathrm{yr}$ & PHMD & III.O & 71.0 & 0.36 & 1.07 \\
\hline 29 & $7 \mathrm{yr}$ & PS & 51.0 & 12.0 & 0.76 & 1.76 \\
\hline 30 & $7 \mathrm{yr}$ & PDA & 104.0 & 28.0 & 0.73 & 1.28 \\
\hline 31 & $8 \mathrm{yr}$ & AS & 51.6 & 23.2 & 0.52 & 0.60 \\
\hline 32 & $8 \mathrm{yr}$ & VSD and PS & III. 6 & 46.5 & 0.59 & 0.84 \\
\hline 33 & $9 \mathrm{yr}$ & Coarct & 78.0 & 17.0 & 0.78 & 1.22 \\
\hline 34 & $9 \mathrm{yr}$ & AS & 79.0 & Ir.o & 0.85 & I. 54 \\
\hline 35 & $9 \mathrm{yr}$ & PS & 100.0 & 43.3 & 0.57 & 0.97 \\
\hline 36 & IO $\mathrm{yr}$ & SM & 87.0 & 27.0 & 0.69 & 1.47 \\
\hline 37 & II yr & SM & 86.2 & 24.4 & 0.72 & 1.39 \\
\hline 38 & II yr & ASD & II5.6 & 29.2 & 0.75 & 1.75 \\
\hline 39 & $12 \mathrm{yr}$ & VSD & 97.2 & 18.5 & 0.81 & I.19 \\
\hline 40 & $16 \mathrm{yr}$ & SM & 106.7 & 41.3 & $0.6 \mathrm{I}$ & 0.91 \\
\hline
\end{tabular}

Key: EDV, end-diastolic volume; ESV, end-systolic volume; EF, ejection fraction; Mean Vcf, mean rate of circumferential fibre shortening; PAT, paroxysmal atrial tachycardia; Coarct, coarctation of the aorta; VSD, ventricular septal defect; PDA, persistent ductus arteriosus; PHMD, primary heart muscle disease; TGA, transposition of the great arteries; MR, mitral regurgitation; PS, pulmonary stenosis; CHB, complete heart block; BT, Blalock-Taussig operation; PVT, paroxysmal ventricular tachycardia; AS, aortic stenosis; SM, systolic murmur with no structural cause; ASD, atrial septal defect.

fibre shortening (Mean Vcf) (Karliner et al., 197I) was obtained using the formula:

$$
\text { Mean Vcf }=\frac{\text { EDD }- \text { ESD }}{\text { Ejection time } \times \text { EDD }} \text { (Cooper et al., 1972) }
$$

where EDD and ESD are the end-diastolic and endsystolic dimensions, respectively, measured as described above. Ejection time was taken as the time elapsed between the onset of inward movement of the septum and posterior left ventricular wall to the point of their closest approximation. Since isovolumic contraction is not isometric this method may give rise to errors in the estimation of ejection time.
The angiocardiographic and echocardiographic estimates of end-diastolic volume, end-systolic volume, ejection fraction, and mean Vcf were then compared using linear regression analysis. The null hypothesis was retained when its probability exceeded 0.05 .

\section{Results}

Table I gives the ages and diagnoses of all 40 patients as well as angiocardiographic and echocardiographic estimates of left ventricular enddiastolic volume, end-systolic volume, ejection fraction, and mean Vcf. 
TABLE 2 Results of regression analysis

\begin{tabular}{|c|c|c|c|}
\hline \multicolumn{2}{|c|}{ Echocardiographic values } & \multirow[b]{2}{*}{$E F$} & \multirow[b]{2}{*}{$\begin{array}{l}\text { Mean } \\
V c f(c i r c / s)\end{array}$} \\
\hline$E D V\left(\mathrm{ml} / \mathrm{m}^{2}\right)$ & $E S V\left(m l / m^{2}\right)$ & & \\
\hline 44.0 & 20.4 & 0.54 & 1.03 \\
\hline 36.4 & 7.2 & 0.80 & 2.40 \\
\hline 48.3 & 21.8 & 0.55 & 1.29 \\
\hline 38.6 & 6.1 & 0.84 & 2.91 \\
\hline 79.0 & 44.0 & 0.44 & 0.65 \\
\hline 88.5 & 20.8 & 0.77 & 1.37 \\
\hline 53.9 & 9.5 & 0.82 & 2.90 \\
\hline 201.0 & 159.0 & $0.2 \mathrm{I}$ & 0.26 \\
\hline 40.1 & 16.5 & 0.59 & 1.06 \\
\hline 83.0 & 30.0 & 0.64 & 1.31 \\
\hline 48.3 & 14.0 & 0.70 & 1.20 \\
\hline 102.0 & 24.0 & 0.76 & 1.75 \\
\hline 132.0 & 37.0 & 0.72 & 1.25 \\
\hline 129.0 & 39.0 & 0.70 & I.39 \\
\hline 64.0 & 20.0 & 0.69 & 1.63 \\
\hline 241.0 & 137.0 & 0.43 & 0.86 \\
\hline 67.0 & 22.0 & 0.67 & 1.23 \\
\hline 99.0 & 23.0 & 0.77 & 1.12 \\
\hline 46.0 & 17.0 & 0.61 & 1.05 \\
\hline 76.0 & 23.0 & 0.70 & 1.06 \\
\hline I64.0 & 124.2 & 0.24 & 0.38 \\
\hline 54.0 & 15.0 & 0.72 & 1.09 \\
\hline 98.6 & 37.5 & 0.62 & 1.72 \\
\hline 168.5 & 38.0 & 0.77 & 2.06 \\
\hline 62.7 & $\mathrm{r} 4.8$ & 0.76 & I.10 \\
\hline 103.0 & 24.0 & 0.76 & $\mathrm{r} .45$ \\
\hline 50.0 & 19.0 & 0.62 & 0.81 \\
\hline 191.0 & 103.0 & 0.46 & 0.85 \\
\hline 60.2 & I 4.4 & 0.76 & 1.80 \\
\hline 82.0 & 32.0 & 0.61 & 1.05 \\
\hline 60.0 & 38.9 & 0.36 & 0.52 \\
\hline 68.0 & 22.0 & 0.68 & 0.98 \\
\hline 81.0 & 13.0 & 0.84 & 1.50 \\
\hline 74.I & 25.9 & 0.65 & 1.29 \\
\hline 70.1 & 17.1 & 0.76 & 1.17 \\
\hline 61.0 & 16.7 & 0.73 & I.39 \\
\hline 50.0 & 16.9 & 0.68 & 1.42 \\
\hline 24.6 & 5.4 & 0.78 & 1.42 \\
\hline 59.3 & 25.0 & 0.58 & 0.78 \\
\hline 109.0 & 49.4 & 0.55 & 1.22 \\
\hline
\end{tabular}

\section{End-diastolic volume}

Angiocardiographic estimates ranged from 26.5 $\mathrm{ml} / \mathrm{m}^{2}$ to $234 \mathrm{ml} / \mathrm{m}^{2}$ (mean $98.8 \mathrm{ml} / \mathrm{m}^{2}$ ). The echocardiographic estimates ranged from $24.6 \mathrm{ml} / \mathrm{m}^{2}$ to $24 \mathrm{I} \mathrm{ml} / \mathrm{m}^{2}$ (mean $85.2 \mathrm{ml} / \mathrm{m}^{2}$ ).

When the results were compared the correlation coefficient was $0.76(P<0.001)$ and the standard error of the estimate was $31.6 \mathrm{ml} / \mathrm{m}^{2}$ (Table 2).

\section{End-systolic volume}

Angiocardiographic estimates ranged from $3.5 \mathrm{ml} / \mathrm{m}^{2}$ to $213 \mathrm{ml} / \mathrm{m}^{2}$ (mean $36.5 \mathrm{ml} / \mathrm{m}^{2}$ ). The echocardiographic estimates ranged from $5.4 \mathrm{ml} / \mathrm{m}^{2}$ to 159 $\mathrm{ml} / \mathrm{m}^{2}$ (mean $33.6 \mathrm{ml} / \mathrm{m}^{2}$ ). When the results were

\begin{tabular}{|c|c|}
\hline End-diastolic volume $\left(\mathrm{ml} / \mathrm{m}^{2}\right)$ & $\begin{array}{l}\text { Echo }=5.3 \mathrm{I}+0.8 \mathrm{I} \times \text { angio } \\
\mathrm{r}=0.76 \\
\mathrm{P}<0.00 \mathrm{I} \\
\mathrm{SEE}=31.6 \mathrm{ml} / \mathrm{m}^{2}\end{array}$ \\
\hline End-systolic volume $\left(\mathrm{ml} / \mathrm{m}^{2}\right)$ & $\begin{array}{l}\text { Echo }=5.3+0.78 \times \text { angio } \\
r=0.68 \\
P<0.00 \mathrm{r} \\
\text { SEE }=19.8 \mathrm{ml} / \mathrm{m}^{2}\end{array}$ \\
\hline Ejection fraction & $\begin{array}{l}\text { Echo }=0.24+0.62 \times \text { angio } \\
r=0.73 \\
P<0.001 \\
S E E=0.1 \mathrm{ml} / \mathrm{m}^{2}\end{array}$ \\
\hline $\begin{array}{l}\text { Mean rate of circumferential } \\
\text { fibre shortening }\end{array}$ & $\begin{array}{l}\text { Echo }=0.2 \mathrm{I}+0.83 \times \text { angio } \\
\mathrm{r}=0.9 \mathrm{I} \\
\mathrm{P}<0.00 \mathrm{I} \\
\mathrm{SEE}=0.22 \mathrm{ml} / \mathrm{m}^{2}\end{array}$ \\
\hline
\end{tabular}

Echo, echocardiographic estimate; Angio, angiocardiographic estimate. SEE, standard error of the estimate.

compared the correlation coefficient was $0.68(\mathrm{P}<$ $0.00 \mathrm{I})$ and the standard error of estimate was $19.8 \mathrm{ml} / \mathrm{m}^{2}$ (Table 2).

\section{Ejection fraction}

Angiocardiographic estimates ranged from 0.92 to 0.06 (mean 0.67 ) and the echocardiographic values from 0.84 to 0.21 (mean 0.65). When the two methods were compared the correlation coefficient was $0.73(P<0.001)$ and the standard error of the estimate was 0.10 (Table 2).

\section{Mean Vef}

Angiocardiographic values using diameters at the mid-point of the long axis ranged from 0.07 to $3.25 \mathrm{circ} / \mathrm{s}$ (mean r.3I) (Table 2).

Echocardiographic values ranged from 0.26 to 2.9I circ/s (mean I.29). Comparison of echocardiographic data with values measured at the midpoint of the long axis on the angiogram gave a correlation of $0.91 \quad(P<0.001)$ and a standard error of the estimate of $0.22 \mathrm{circ} / \mathrm{s}$. Taking the lower limit of normal for mean Vcf as I circ/s, there were 3 patients in whom the angiocardiogram suggested diminished left ventricular function but the echocardiographic estimate was normal. In a further 3 patients where the angiogram suggested normal function the echocardiographic estimate was less than I circ/s (Fig.).

\section{Discussion}

Echocardiographic estimates of left ventricular function have found a considerable measure of support in adult cardiology. Their usefulness has been suggested in the assessment of the effect of inotropic interventions (Kraunz and Kennedy, 1970; Kraunz and Ryan, 197I), for the evaluation of patients with 


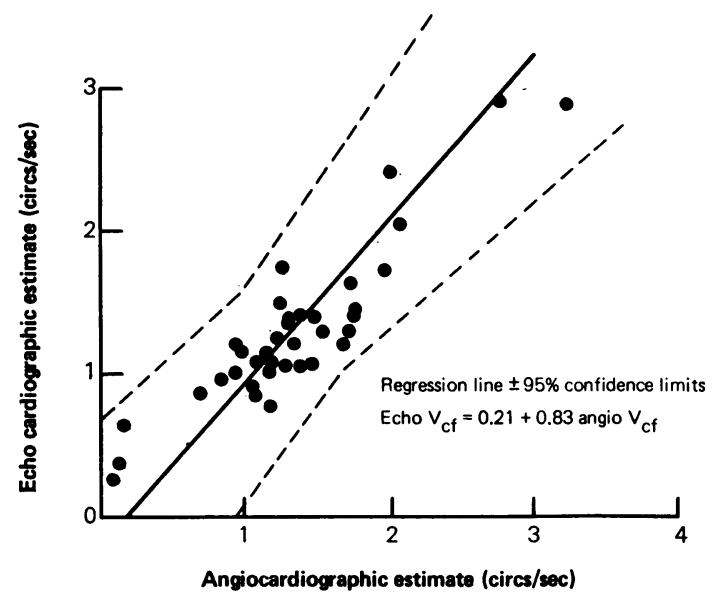

FIG. I Comparison of mean rate of circumferential shortening by the angiocardiographic method, and the echocardiographic method. Broken lines indicate 95 per cent confidence limits.

mitral or aortic regurgitation (Popp and Harrison, 1970) and in the evaluation of pressure/dimension relations of the left ventricle (Gibson and Brown, 1973; McLaurin et al., 1973).

However, the place of echo-derived estimates of left ventricular volume and function in paediatric and adult practice remains undefined. In a recent article, Feigenbaum (1973) has stressed that the relation between the cube of the left ventricular dimension, measured by echocardiography, and the left ventricular volume is empirical and must be used with caution. The present study re-emphasizes this caveat. Though comparison of echographic estimates of end-diastolic and end-systolic volumes with those obtained using a well-validated angiocardiographic method does show a highly significant correlation, there is a large standard error. Similar results have been reported by workers in adult cardiology (Popp et al., 1969; Pombo et al., 1971; Fortuin et al., 197I ; Gibson, 1973) suggesting that at all ages great caution must be used in interpreting the volumetric data obtained using echocardiography.

Several sources of error exist, one being in the calibration of the distance measurements. Static calibration in blood at $37^{\circ} \mathrm{C}$ revealed an error of 2 per cent. This becomes an error of +8 per cent when using the cube function. A second source of error is in the registration of the endocardial image on polaroid film. It has been suggested that the use of a strip chart recorder may increase the accuracy of endocardial delineation while also facilitating the correct orientation of the echo beam (Feigen- baum, 1973). Alterations in spatial orientation of the left ventricle within the chest by chamber enlargement associated with mitral stenosis or right ventricular volume overload, have been shown to affect single plane angiocardiographic estimation of left ventricular volume (Levenson et al., 1973; Hunter et al., 1974). These factors may also apply to echocardiography.

Finally, in the infant the mitral valve appears to extend a much longer distance into the left ventricle (Sahn et al., 1974) so that accurate beam orientation may be less easy than in the adult.

However, the major errors are in the model used for the calculation of left ventricular volume and with present techniques these errors are ineradicable. The mean Vcf avoids the use of cube functions when calculated from echocardiograms and employs the fewest assumptions of left ventricular geometry when cine angiocardiography is used. Theoretically it should be a more satisfactory echo index of ventricular function than those dependent on ventricular volume calculations, and the results presented in this paper support this. Significant correlation between the mean Vcf obtained from the echo and from the cine has also been demonstrated in adults (Cooper et al., 1972) and in a small series of newborns (Sahn et al., 1974). Moreover, Fortuin, Hood, and Craige (1972) have found the measurement useful in differentiating normal from abnormal left ventricular function. In their series, as in ours, some overlap was seen in the results obtained from patients with nor$\mathrm{mal}$ and abnormal function. However, the overlap does not invalidate the echocardiogram as a source of useful information about left ventricular performance in infants and children, and its value may be enhanced by incorporating it into a stress testing protocol.

From our limited experience of sequential examinations in infants, it appears probable that the echocardiographic mean Vcf will be of most value in the serial study of individual patients, and it is this type of investigation for which echocardiography is ideally suited.

This work was supported by a grant from the British Heart Foundation.

\section{References}

Cooper, R. H., O'Rourke, R. A., Karliner, J. S., Peterson, K. L., and Leopold, G. R. (1972). Comparison of ultrasound and cineangiographic measurements of the mean rate of circumferential fiber shortening in man. Circulation, 46, 914 .

Dodge, H. T. (197I). Determination of left ventricular volume and mass. Radiologic Clinics of North America, 9, 459.

Feigenbaum, H. (1973). Newer aspects of echocardiography. Circulation, 47, 833. 
Feigenbaum, H., Wolfe, S. B., Popp, R. L., Haine, C. L., and Dodge, H. T. (1969). Correlation of ultrasound with angiocardiography in measuring left ventricular diastolic volume (abstract). American fournal of Cardiology, 23, II I.

Fortuin, N. J., Hood, W. P., and Craige, E. (1972). Evaluation of left ventricular function by echocardiography. Circulation, 46, 26.

Fortuin, N. J., Hood, W. P., Sherman, M. E., and Craige, E. (197I). Determination of left ventricular volumes by ultrasound. Circulation, 44, 575.

Gibson, D. G. (1973). Estimation of left ventricular size by echocardiography. British Heart fournal, 35, 128.

Gibson, D. G., and Brown, D. (1973). Measurement of instantaneous left ventricular dimension and filling rate in man, using echocardiography. British Heart fournal, 35, II4I.

Hunter, A. S., Gentzler, R. D., Gault, J. H., and Vincent, W. R. (1974). Distortion of left ventricular chamber anatomy by right ventricular volume overload (abstract). American fournal of Cardiology, 33, 145.

Karliner, J. W., Gault, J. H., Eckberg, D., Mullins, C. B., and Ross, J. (I97I). Mean velocity of fiber shortening; a simplified measure of left ventricular myocardial contractility. Circulation, 44, 323.

Kraunz, R. F., and Kennedy, J. W. (1970). An ultrasonic determination of left ventricular wall motion in normal man. American Heart fournal, 79, 36.

Kraunz, R. F., and Ryan, T. J. (I97I). Ultrasonic measurements of ventricular wall motion following administration of vasoactive drugs. American fournal of Cardiology, 27, 464 .
Levenson, L. W., Liedtke, A. J., Hunter, A. S., Gentzler, R. D., and Gault, J. H. (1973). Left ventricular chamber distortion in mitral stenosis (abstract). Circulation, 47 and 48, Suppl. IV., p. 117 .

McLaurin, L. P., Grossman, W., Stefadouros, M. A., Rolett, E. L., and Young, D. T. (1973). A new technique for the study of left ventricular pressure - volume relations in man. Circulation, 48, 56.

Pombo, J., Troy, B., and Russell, R. (197I). Left ventricular volume and ejection fraction by ultrasound. Circulation, 43, 480 .

Popp, R. L., and Harrison, D. C. (1970). Ultrasonic cardiac echography for determining stroke volume and valvular regurgitation. Circulation, 4I, 493.

Popp, R. L., Wolfe, S. B., Hirata, T., and Feigenbaum, H. (1969). Estimation of right and left ventricular size by ultrasound. American fournal of Cardiology, 24, 523.

Sahn, D. J., Deely, W. J., Hagan, A. D., and Friedman, W. F. (1974). Echocardiographic assessment of left ventricular performance in normal newborns. Circulation, 49, 232.

Tynan, M., Reid, D. S., Hunter, S., Kaye, H. H., Osme, S., Urquhart, W., and Davies, P. (1975). Ejection phase indices of left ventricular performance in infants, children, and adults. British Heart fournal, 37, 196.

Requests for reprints to Dr. Stewart Hunter, Department of Cardiology, Newcastle General Hospital, Westgate Road, Newcastle upon Tyne NE4 6BE. 